\title{
Preferential incorporation of trans, trans-conjugated linoleic acid isomers into the liver of suckling rats
}

\author{
Lin Yang ${ }^{1,2}$, Sai Ying Venus Yeung ${ }^{2}$, Yu Huang ${ }^{3}$, Han Qing Wang ${ }^{1}$ and Zhen-Yu Chen ${ }^{2}$ \\ ${ }^{1}$ State Key Laboratory of OXO Synthesis \& Selective Oxidation, Lanzhou Institute of Chemical Physics, The Chinese \\ Academy of Sciences, Lanzhou, The People's Republic of China \\ ${ }^{2}$ Department of Biochemistry, The Chinese University of Hong Kong, Shatin, New Territories, Hong Kong, The People's \\ Republic of China \\ ${ }^{3}$ Department of Physiology, The Chinese University of Hong Kong, Shatin, New Territories, Hong Kong, The People's \\ Republic of China
}

(Received 6 June 2001 - Revised 16 October 2001 - Accepted 28 November 2001)

\begin{abstract}
The present study was designed to compare the conjugated linoleic acid (CLA) isomeric distribution pattern in the liver of suckling rats in relation to those in the milk and maternal diet. Silver-ion HPLC was used to separate individual CLA isomers. It was found that the isomeric distribution pattern in the milk was very similar to that in the maternal dietary fat. However, the CLA isomeric distribution patterns in the liver phospholipids (PL) and triacylglycerols were different from those in the diet and milk. In the liver PL, total cis/trans isomers accounted for $63.6-63.9 \%$ of total CLA, which was in contrast to the values of $88.1-89.1 \%$ in the milk and diet. In the liver PL, total trans/trans isomers were 20.6-20.8\% of the total CLA isomers whereas they were only $2.6-3.7 \%$ in the milk and diet. It is concluded that trans/trans-CLA were preferentially incorporated into the liver whereas for the incorporation of cis/trans-CLA there was partial discrimination.
\end{abstract}

Conjugated linoleic acids: Milk: Neonate: Phospholipids: Triacylglycerols

Conjugated linoleic acids (CLA) are a group of positional and geometric isomers of conjugated octadecadienoic acid. Silver-ion HPLC (Ag-HPLC) analysis has demonstrated that CLA contains at least twelve isomers (Sehat et al. 1998). CLA is predominantly present in dairy products via biohydrogenation of polyunsaturated fatty acids by rumen bacteria (Kepler \& Tove, 1967; Ha et al. 1989; Chin et al. 1992). CLA can also be chemically prepared by alkali isomerisation of linoleic acid.

There is increasing interest in commercialising CLA as a food ingredient and health supplement because of its possible health benefits associated with its consumption. CLA has been shown to be anticarcinogenic in experimental animals (Scimeca, 1999), hypolipidaemic (Yeung et al. 2000) and anti-atherosclerotic (Lee et al. 1994; Nicolosi et al. 1997). CLA may also enhance immune functions (Cook et al. 1993; Miller et al. 1994) and reduce fat accumulation while it increases muscle and bone mass (Dugan et al. 1997; Li \& Watkins, 1998). A role of CLA as an antioxidant is, however, controversial. Ha et al. (1990) and Ip et al. (1991) showed that CLA had antioxidative activity and proposed this as a possible explanation for the anticarcinogenic and anti-atheroslerotic effect. However, other investigations have found that CLA was a pro-oxidant (van den Berg et al. 1995; Chen et al. 1997).

Increased maternal intake of CLA during lactation has been associated with enhanced growth rate and improved feeding efficiency of suckling neonatal rats (Chin et al. 1994). However, there is no study to date that has examined the relationship between the amount of CLA in milk and that in the maternal diet in non-ruminant mammals. The aim of the present study was to compare the CLA isomeric distribution pattern in the milk and the liver of suckling rats with that in the maternal diet.

\section{Material and methods \\ Diets}

The animals were fed one of two diets containing either no CLA (control) or a $2 \%$ CLA mixture (Bioriginal Food \& Science Corp., Saskatoon, SK, Canada). The control diet

Abbreviations: Ag-HPLC, silver-ion HPLC; $c$, cis; CLA, conjugated linoleic acid; PL, phospholipids; TG, triacylglycerols; $t$, trans.

* Corresponding author: Dr Zhen-Yu Chen, fax +852 2603 5123, email zhenyuchen@cuhk.edu.hk 
was prepared as previously described (Kwan et al. 1998) by mixing the powdered ingredients in the following proportions (g): casein, 235; rapeseed oil, 100; maize starch, 338; sucrose, 243; mineral mix, 35; vitamin mix, 10; cellulose, 32; choline bitartrate, 4 DL-methionine, 3. The CLA-supplemented diet was prepared by adding $2 \%$ CLA mixture to the control diet $(14.6 \mathrm{~g} / \mathrm{kg}$ diet $)$. The diets were stored frozen at $-20^{\circ} \mathrm{C}$.

\section{Animals}

Nine Sprague-Dawley lactating rats (day 1) were divided into two groups (control, $n 3$; CLA-supplemented group, $n$ 6 ). The animals were switched immediately from the chow diet to one of the experimental diets. The rats were housed individually in an animal room at $23^{\circ} \mathrm{C}$ with $12 \mathrm{~h}-12 \mathrm{~h}$ light-dark cycles. Litter sizes were averaged to ten pups per dam. The fresh diets were given to the maternal rats daily, and uneaten food was discarded. Food intake and body weight were measured daily. The rats were given free access to food and fluid. The protocol was reviewed and approved by the Committee of Animal Ethics, The Chinese University of Hong Kong. At days 7 and 14, five pups from each dam were decapitated. The abdomens were opened and the milk in the stomach was collected and stored at $-78^{\circ} \mathrm{C}$ until analysed. The livers of the pups were also retained and stored at $-78^{\circ} \mathrm{C}$ before analysis.

\section{Fatty acid analysis}

Total lipids derived from the milk were extracted using chloroform-methanol $(2: 1, \mathrm{v} / \mathrm{v})$ containing triheptadecanoic acid as an internal standard. To determine the milk fatty acid composition, acid-catalysed methylation was used in the present study. In brief, the milk lipids samples $(10-20 \mathrm{mg})$ were transesterified in $2 \mathrm{ml}$ of $14 \%(\mathrm{v} / \mathrm{v}) \mathrm{BF}_{3}$ in methanol under $\mathrm{N}_{2}$. The methylation tube was placed in a heat block at $85^{\circ} \mathrm{C}$ for $30 \mathrm{~min}$ and then cooled to room temperature. Hexane $(4 \mathrm{ml})$ and $3 \mathrm{ml}$ distilled water were then added and mixed thoroughly. After centrifugation, the top hexane layer containing fatty-acid methyl esters was saved and subjected to GLC analysis.

The liver lipids were similarly extracted with chloroform-methanol mixture containing triheptadecanoic acid and $\mathrm{L}-\alpha-$-phosphatidylcholine diheptadecanoyl as internal standards to quantify the triaclyglycerols (TG) and phospholipids (PL), respectively. The chloroform-methanol phase was dried under a gentle stream of $\mathrm{N}_{2}$ and redissolved in chloroform, which was then applied to a TLC plate $(20 \times 20 \mathrm{~cm}$, pre-coated with $250 \mu \mathrm{m}$ silica gel $60 \AA$; Macherey-Naged, Duren, Germany) to separate different lipid classes. A solvent system of hexane-diethyl ether-acetic acid (80:20:10, by vol.) was used for development. The bands containing TG and PL were scratched off the plate, and the lipids extracted were converted to methyl esters described above.

The fatty-acid methyl ester mixtures obtained from milk and liver were analysed on a flexible silica capillary column (SP 2560, $100 \mathrm{~m} \times 0.25 \mathrm{~mm}$ internal; Supelco, Inc., Bellefonte, PA, USA) in a HP 5980 Series II gasliquid chromatograph equipped with a flame-ionisation detector and an automated injector (Palo Alto, CA, USA) according to the method we previously described (Chen et al. 1997; Yang et al. 2000). Column temperature was programmed from 180 to $220^{\circ} \mathrm{C}$ at a rate of $1^{\circ} \mathrm{C} / \mathrm{min}$ and then held for $12 \mathrm{~min}$. Injector and detector temperature were set at $250^{\circ} \mathrm{C}$ and $300^{\circ} \mathrm{C}$, respectively. $\mathrm{H}_{2}$ was used as the carrier gas at a head pressure of $105 \mathrm{kPa}$.

\section{Silver-ion high performance liquid chromatography}

To minimize the intra-isomerisation among the CLA isomers, Ag-HPLC was used to separate the individual CLA isomers as a form of non-esterified fatty acids instead of CLA methyl esters according to Ostrowska et al. (2000). In brief, a sample of the total milk or liver lipids $(20 \mathrm{mg})$ was saponified in $5 \mathrm{ml}$ of $6 \% \mathrm{KOH}$ in ethanol under $\mathrm{N}_{2}$ with constant stirring for $9 \mathrm{~h}$ at room temperature. The mixture was then acidified with $5 \mathrm{ml}$ of $2.0 \mathrm{M} \mathrm{HCl}$ and $10 \mathrm{ml}$ distilled water. The non-esterified fatty acids were then extracted three times with $5 \mathrm{ml}$ hexane. The individual CLA isomers were separated using an Alltech Model 525 HPLC equipped with a ternary pump delivery system. In brief, $5 \mu \mathrm{l}$ of free CLA isomers $(5 \mu \mathrm{g} / \mathrm{ml})$ in hexane was injected onto an Ag-impregnated column $(4.6 \mathrm{~mm}$ internal diameter $\times 250 \mathrm{~mm}$ stainless, $5 \mu \mathrm{m}$; Chrompack, Bridgewater, NJ, USA) via a rheodyne valve injector. Hexane containing $1.4 \%(\mathrm{v} / \mathrm{v})$ acetic acid and $0.014 \%(\mathrm{v} / \mathrm{v})$ acetonitrile was chosen as a mobile phase at a flow rate of $1.0 \mathrm{ml} / \mathrm{min}$. The separated individual CLA isomers were quantified at $233 \mathrm{~nm}$ using a u.v. detector (UVIS-205; Alltech, Deerfield, IL, USA).

\section{Statistics}

Data are expressed as means and standard deviations. Where applicable, ANOVA was used to statistically evaluate significant differences among the control and CLAsupplemented group using Sigmastat (Jandel Scientific Software, San Rafael, CA, USA). Differences were considered significant when $P<0 \cdot 05$.

\section{Results \\ Fatty acid composition of dietary fat}

The control maternal rats were fed a diet containing rapeseed oil while the CLA group was fed the same diet but supplemented with a $2 \%$ CLA commercial mixture. The gas chromatographic analysis showed that the CLA mixture contained $66.6 \%$ CLA, $19.0 \%$ oleic acid, $5.6 \%$ palmitic acid, $3.5 \%$ stearic acid and $2.2 \%$ linoleic acid. As shown in Table 1, CLA was absent in the control diet but it accounted for $14.6 \mathrm{~g} / \mathrm{kg}$ diet or $12.7 \%$ total fatty acids in the CLA-supplemented diet.

\section{Weights of stomach milk, body and liver of suckling rats}

There were no significant differences in the body-weight gain and liver weight between the control and CLA suckling rats (Table 2). The milk content obtained from the stomach ranged between 0.12 to $0.16 \mathrm{~g} /$ suckling rat. 
Table 1. Fatty acid composition of dietary fat

\begin{tabular}{|c|c|c|c|c|}
\hline \multirow[b]{2}{*}{ Fatty acids } & \multicolumn{2}{|r|}{ Control } & \multicolumn{2}{|c|}{ CLA supplementation } \\
\hline & $\mathrm{g} / \mathrm{kg}$ diet & $\%$ total fatty acids & $\mathrm{g} / \mathrm{kg}$ diet & $\%$ total fatty acids \\
\hline $16: 0$ & 5.4 & $5 \cdot 7$ & 6.5 & 5.6 \\
\hline $18: 0$ & $2 \cdot 4$ & 2.5 & $3 \cdot 2$ & $2 \cdot 8$ \\
\hline $20: 0$ & 0.7 & 0.7 & 0.7 & 0.6 \\
\hline $22: 0$ & $<0.1$ & $<0.1$ & 0.1 & 0.1 \\
\hline Total saturates & $8 \cdot 6$ & $9 \cdot 1$ & $10 \cdot 5$ & $9 \cdot 1$ \\
\hline $16: 1 n-7$ & 0.3 & 0.3 & 0.3 & 0.3 \\
\hline $18: 1 n-9$ & $56 \cdot 0$ & $59 \cdot 0$ & $59 \cdot 8$ & $52 \cdot 1$ \\
\hline $20: 1 n-9$ & $1 \cdot 8$ & 1.9 & 1.8 & 1.6 \\
\hline $22: 1 n-9$ & 0.3 & 0.3 & 0.3 & 0.3 \\
\hline Total monounsaturates & $58 \cdot 4$ & $62 \cdot 0$ & $62 \cdot 2$ & $54 \cdot 2$ \\
\hline $18: 2 n-6$ & $19 \cdot 6$ & $20 \cdot 8$ & $20 \cdot 0$ & $17 \cdot 4$ \\
\hline $18: 3 n-3$ & $6 \cdot 9$ & $7 \cdot 3$ & $6 \cdot 9$ & $6 \cdot 0$ \\
\hline Total trans-fatty acids & 0.6 & 0.6 & 0.6 & 0.5 \\
\hline CLA & $<0.1$ & $<0.1$ & $14 \cdot 6$ & $12 \cdot 7$ \\
\hline
\end{tabular}

CLA, conjugated linoleic acid.

However, no significant difference in the milk content was observed between the control and suckling rats.

\section{Milk fatty acid composition}

Supplementation of CLA mixture $(14.6 \mathrm{~g} / \mathrm{kg}$ diet $)$ in the maternal diet significantly increased the CLA content in the milk. As shown in Table 3, the CLA group had a level of $7 \cdot 8-8.6 \%$ CLA of total fatty acids compared with the undetectable level of the control rats. Addition of the CLA mixture to the maternal diet did not change the content of longer-chain polyunsaturated $n-6$ and $n-3$ fatty acids with a $\mathrm{C}$ number $\geqq 20$. However, myristic acid $(14: 0)$ in the milk of the CLA-supplemented group was significantly lowered compared with the control value at both day 7 and 14. Lauric acid (12:0) and oleic acid $(18: 1 n-9)$ and linolenic acid $(18: 3 n-3)$ were lower compared with the control only at day 7 . It appeared that total milk fat was reduced in the CLA-supplemented group. However, significant difference was only found at day 7.

\section{Fatty acid composition in the liver phospholipids of suckling rats}

Supplementation of $14.6 \mathrm{~g} \mathrm{CLA} / \mathrm{kg}$ diet in the maternal diet led to the incorporation of $7 \cdot 8-8.6 \%$ CLA in the milk lipids (Table 3). The gas chromatographic analysis demonstrated that the CLA incorporated into the liver PL of suckling rats accounted for only $0.5-0.8 \%$ total fatty acids (Table 4). CLA supplementation in the maternal diet at the level of $14.6 \mathrm{~g} / \mathrm{kg}$ diet did not change the composition of other fatty acids in the liver PL of suckling rats except for $18: 1 n-9$, which was significantly lower in the CLA-supplemented group compared with the control value (Table 4).

Conjugated linoleic acid isomeric distribution in the maternal diet, milk and the liver phospholipids of suckling rats

Ag-HPLC analysis showed that the CLA in the diet contained $89.1 \% \mathrm{cis}(\mathrm{c}) / \operatorname{trans}(t)$ isomers, $8.3 \% \mathrm{c} / \mathrm{c}$ isomers and $2.6 \% \mathrm{t} / \mathrm{t}$ isomers expressed as percentage of total CLA content (Table 5; Fig. 1). Among four $c / t$ isomers, $10 c, 12 t / 10 t, 12 c$-CLA was most abundant $(27.5 \%)$ followed by $11 c, 13 t / 11 t, 13 c$-CLA $(25.5 \%), 9 c, 11 t / 9 t$, $11 c$-CLA $(20.2 \%)$ and $8 c, 10 t / 8 t, 10 c$-CLA $(15.9 \%)$ in decreasing order. Among five $t / t$ isomers, 8t, 10t-CLA, $9 t, 11 t$-CLA, 10t, 12t-CLA and 11t, 13t-CLA accounted for $1.1 \%, 1.0 \%, 0.3 \%$ and $0.3 \%$ respectively. $8 c$, $10 c$-CLA, $9 c, 11 c$-CLA and 10c, 12c-CLA were the major $c / c$ isomers; each accounted for $2.7 \%$ total CLA.

The isomeric distribution pattern in the milk was very

Table 2. Weights of stomach milk and liver of suckling rats*

(Mean values with their standard deviations)

\begin{tabular}{|c|c|c|c|c|c|c|c|c|}
\hline & \multicolumn{4}{|c|}{ Day 7} & \multicolumn{4}{|c|}{ Day 14} \\
\hline & \multicolumn{2}{|c|}{ Control } & \multicolumn{2}{|c|}{ CLA } & \multicolumn{2}{|c|}{ Control } & \multicolumn{2}{|c|}{ CLA } \\
\hline & Mean & SD & Mean & SD & Mean & SD & Mean & SD \\
\hline Body weight (g/pup) & $16 \cdot 0$ & $2 \cdot 0$ & $16 \cdot 3$ & 1.9 & $22 \cdot 5$ & $1 \cdot 7$ & $24 \cdot 8$ & $3 \cdot 6$ \\
\hline Liver weight (g/pup) & $0 \cdot 6$ & $0 \cdot 1$ & 0.5 & 0.1 & 1.3 & 0.1 & $1 \cdot 3$ & 0.1 \\
\hline Milk in stomach (g/pup) & 0.16 & 0.5 & 0.14 & 0.08 & $0 \cdot 12$ & 0.02 & 0.14 & 0.10 \\
\hline
\end{tabular}

CLA, conjugated linoleic acid.

${ }^{*}$ For details of diets and procedures, see Table 1 and p. 254. 
Table 3. Milk fatty-acid composition in the control and conjugated linoleic acid (CLA)-supplemented rats*

(Mean values with their standard deviations)

\begin{tabular}{|c|c|c|c|c|c|c|c|c|}
\hline & \multicolumn{4}{|c|}{ Day 7} & \multicolumn{4}{|c|}{ Day 14} \\
\hline & \multicolumn{2}{|c|}{ Control } & \multicolumn{2}{|c|}{ CLA } & \multicolumn{2}{|c|}{ Control } & \multicolumn{2}{|c|}{ CLA } \\
\hline & Mean & SD & Mean & SD & Mean & $\mathrm{SD}$ & Mean & SD \\
\hline $12: 0$ & $8 \cdot 7$ & 0.5 & $6 \cdot 7 \dagger$ & 0.8 & 13.9 & 0.1 & $11 \cdot 1$ & $3 \cdot 7$ \\
\hline $14: 0$ & $8 \cdot 8$ & 0.1 & $5 \cdot 7 \dagger$ & 1.4 & $11 \cdot 1$ & $1 \cdot 1$ & $6.9 \dagger$ & 1.6 \\
\hline $16: 0$ & $19 \cdot 3$ & 0.3 & $18 \cdot 4$ & 0.9 & $16 \cdot 9$ & $1 \cdot 3$ & $16 \cdot 4$ & $2 \cdot 6$ \\
\hline $18: 0$ & $3 \cdot 1$ & 0.2 & $4 \cdot 2$ & 0.2 & 3.7 & 0.7 & $4 \cdot 3$ & $1 \cdot 2$ \\
\hline $18: 1 n-9$ & $38 \cdot 6$ & 1.8 & $35 \cdot 3 \dagger$ & 1.9 & 34.6 & $2 \cdot 6$ & $33 \cdot 3$ & 4.3 \\
\hline $20: 1 n-9$ & 1.0 & $0 \cdot 1$ & 1.4 & 0.2 & 0.9 & $0 \cdot 1$ & $1.5 \dagger$ & 0.2 \\
\hline $20: 1 n-7$ & 0.2 & 0.1 & 0.3 & 0.1 & 0.2 & 0.1 & 0.3 & 0.1 \\
\hline $18: 2 n-6$ & $12 \cdot 4$ & 0.3 & $12 \cdot 5$ & $1 \cdot 2$ & $9 \cdot 7$ & 0.8 & $10 \cdot 4$ & $1 \cdot 3$ \\
\hline $18: 3 n-6$ & 0.4 & 0.1 & 0.3 & 0.1 & 0.1 & 0.1 & 0.2 & 0.1 \\
\hline $20: 2 n-6$ & 0.5 & 0.1 & 0.4 & 0.1 & 0.3 & 0.1 & 0.3 & 0.1 \\
\hline $20: 3 n-6$ & 0.6 & 0.1 & 0.4 & 0.1 & 0.2 & 0.1 & 0.2 & 0.1 \\
\hline $20: 4 n-6$ & 1.0 & 0.1 & $1 \cdot 1$ & 0.1 & 0.7 & 0.1 & $0 \cdot 8$ & 0.2 \\
\hline $22: 4 n-6$ & 0.4 & 0.1 & 0.4 & $0 \cdot 1$ & 0.5 & 0.2 & 0.4 & $0 \cdot 1$ \\
\hline $22: 5 n-6$ & 0.2 & $0 \cdot 1$ & $0 \cdot 3$ & $0 \cdot 1$ & $0 \cdot 4$ & $0 \cdot 2$ & 0.5 & 0.3 \\
\hline $18: 3 n-3$ & $2 \cdot 4$ & 0.2 & $2.0 \dagger$ & 0.2 & $2 \cdot 8$ & 0.7 & $2 \cdot 0$ & 0.6 \\
\hline $20: 5 n-3$ & 0.3 & $0 \cdot 1$ & $0 \cdot 2$ & $0 \cdot 1$ & 0.2 & 0.1 & $0 \cdot 1$ & $0 \cdot 1$ \\
\hline $22: 5 n-3$ & 0.3 & 0.1 & 0.2 & 0.1 & 0.2 & 0.1 & 0.2 & 0.1 \\
\hline $22: 6 n-3$ & 0.3 & 0.1 & 0.4 & $0 \cdot 1$ & 0.4 & 0.1 & 0.5 & $0 \cdot 1$ \\
\hline CLA & ND & & $7 \cdot 8$ & 1.3 & ND & & $8 \cdot 6$ & $2 \cdot 3$ \\
\hline Total lipids (mg/g milk) & $340 \cdot 1$ & $115 \cdot 7$ & $227 \cdot 8 \dagger$ & $7 \cdot 6$ & $209 \cdot 1$ & 4.0 & $179 \cdot 3$ & $40 \cdot 2$ \\
\hline
\end{tabular}

similar to that in dietary fat (Table 5; Fig. 1). The statistical analysis indicated that the percentage value of each isomer in the milk was not different from that in the diet. No difference in the isomeric distribution in the milk between day 7 and 14 was observed. However, the CLA isomeric distribution patterns in the liver PL and TG were different from those in the maternal diet and milk (Table 5; Fig. 1). In the liver PL, total $c / t$ isomers accounted for 63.6$63.9 \%$, which was in contrast to the values of $88.1-$ $89.1 \%$ in the milk and diet. In the liver PL, total $t / t$ isomers

Table 4. Fatty-acid composition of liver phospholipids in the control and conjugated linoleic acid (CLA)-supplemented neonatal rats ${ }^{\star}$

(Mean values with their standard deviations)

\begin{tabular}{|c|c|c|c|c|c|c|c|c|}
\hline & \multicolumn{4}{|c|}{ Day 7} & \multicolumn{4}{|c|}{ Day 14} \\
\hline & \multicolumn{2}{|c|}{ Control } & \multicolumn{2}{|c|}{ CLA } & \multicolumn{2}{|c|}{ Control } & \multicolumn{2}{|c|}{ CLA } \\
\hline & Mean & SD & Mean & $\mathrm{SD}$ & Mean & SD & Mean & SD \\
\hline $14: 0$ & 0.7 & 0.1 & 0.4 & 0.1 & 0.6 & 0.1 & 0.5 & 0.1 \\
\hline $16: 0$ & $26 \cdot 3$ & 0.4 & $25 \cdot 7$ & 1.8 & $21 \cdot 8$ & 1.3 & 21.1 & 1.3 \\
\hline $18: 0$ & $23 \cdot 0$ & 0.7 & $22 \cdot 7$ & 1.8 & $22 \cdot 6$ & 0.8 & $24 \cdot 3$ & 1.8 \\
\hline $18: 1 n-9$ & 9.0 & 0.1 & $7.8 \dagger$ & 0.7 & $9 \cdot 1$ & 0.9 & $7 \cdot 8 \dagger$ & 0.8 \\
\hline $20: 1 n-9$ & 0.5 & 0.1 & 0.3 & 0.1 & 0.5 & 0.1 & 0.3 & 0.1 \\
\hline $18: 2 n-6$ & $9 \cdot 0$ & 0.5 & $9 \cdot 2$ & 0.4 & $9 \cdot 6$ & 0.2 & $9 \cdot 4$ & $1 \cdot 2$ \\
\hline $20: 3 n-6$ & 0.9 & 0.1 & 0.8 & 0.1 & 1.0 & 0.1 & 0.7 & 0.1 \\
\hline $20: 4 n-6$ & $16 \cdot 7$ & $1 \cdot 1$ & $17 \cdot 3$ & 1.5 & $19 \cdot 0$ & 1.1 & $18 \cdot 0$ & $1 \cdot 1$ \\
\hline $22: 4 n-6$ & 1.5 & 0.3 & 1.4 & 0.3 & $1 \cdot 7$ & 0.2 & $2 \cdot 0$ & 0.2 \\
\hline $22: 5 n-6$ & 1.5 & 0.1 & $1.0 \dagger$ & 0.1 & 1.9 & 0.1 & 1.2 & 0.1 \\
\hline $18: 3 n-3$ & 0.1 & 0.1 & 0.1 & 0.1 & 0.2 & 0.1 & 0.1 & 0.1 \\
\hline $20: 5 n-3$ & 0.5 & 0.1 & 0.5 & 0.1 & 0.5 & 0.1 & 0.6 & 0.1 \\
\hline $22: 5 n-3$ & 1.3 & 0.1 & 1.0 & 0.2 & 1.5 & 0.1 & $1 \cdot 2$ & 0.1 \\
\hline $22: 6 n-3$ & 8.7 & 0.3 & $10 \cdot 7$ & $2 \cdot 1$ & $10 \cdot 0$ & 1.0 & $11 \cdot 6$ & $1 \cdot 1$ \\
\hline CLA & ND & & 0.5 & 0.2 & ND & & 0.8 & 0.2 \\
\hline Total lipids (mg/g liver) & 11.4 & 0.7 & 14.5 & $6 \cdot 4$ & $19 \cdot 0$ & $1 \cdot 2$ & $16 \cdot 6$ & 1.3 \\
\hline
\end{tabular}

ND, not detected.

* For details of diets and procedures, see Table 1 and p. 254

$\dagger$ Mean values were significantly different from those of the control group, $P<0.05$. 
Table 5. Relative composition of conjugated linoleic acid (CLA) isomers as percentage of the total CLA in the maternal diet, the milk and the neonatal liver phospholipids (PL) and triacylglycerols (TG)*

(Mean values with their standard deviations)

\begin{tabular}{|c|c|c|c|c|c|c|c|c|c|c|c|c|c|c|}
\hline & & & \multicolumn{4}{|c|}{ Milk } & \multicolumn{4}{|c|}{ Liver PL } & \multicolumn{4}{|c|}{ Liver TG } \\
\hline & \multicolumn{2}{|c|}{ Diet } & \multicolumn{2}{|c|}{ Day 7} & \multicolumn{2}{|c|}{ Day 14} & \multicolumn{2}{|c|}{ Day 7} & \multicolumn{2}{|c|}{ Day 14} & \multicolumn{2}{|c|}{ Day 7} & \multicolumn{2}{|c|}{ Day 14} \\
\hline & Mean & SD & Mean & SD & Mean & SD & Mean & SD & Mean & SD & Mean & SD & Mean & SD \\
\hline $11 t, 13 t-18: 2$ & $0.3^{b}$ & 0.1 & $0.4^{b}$ & 0.1 & $0.4^{b}$ & 0.2 & $6 \cdot 8^{a}$ & 0.2 & $7 \cdot 7^{a}$ & 0.2 & $6 \cdot 5^{a}$ & $1 \cdot 1$ & $6 \cdot 2^{a}$ & 1.5 \\
\hline $10 t, 12 t-18: 2$ & $0.3^{\mathrm{b}}$ & 0.1 & $0.3^{\mathrm{b}}$ & 0.2 & $0.3^{\mathrm{b}}$ & 0.2 & $3 \cdot 8^{a}$ & 0.1 & $3.5^{\mathrm{a}}$ & 0.1 & $4 \cdot 1^{\mathrm{a}}$ & $1 \cdot 1$ & $5 \cdot 3^{a}$ & 1.6 \\
\hline $9 t, 11 t-18: 2$ & $1.0^{\mathrm{b}}$ & 0.1 & $1.3^{\mathrm{b}}$ & 0.2 & $1.7^{\mathrm{b}}$ & 0.2 & $4 \cdot 9^{a}$ & 0.3 & $4 \cdot 7^{\mathrm{a}}$ & 0.2 & $4 \cdot 5^{a}$ & 1.8 & $4 \cdot 9^{a}$ & 1.7 \\
\hline $8 t, 10 t-18: 2$ & $1 \cdot 1^{\mathrm{b}}$ & 0.1 & $1 \cdot 7^{\mathrm{b}}$ & 0.1 & $1.0^{\mathrm{b}}$ & 0.2 & $5 \cdot 1^{\mathrm{a}}$ & 0.3 & $4 \cdot 9^{a}$ & 0.3 & $3.9^{a}$ & 1.7 & $3 \cdot 0^{\mathrm{a}}$ & 0.8 \\
\hline Subtotal & $2 \cdot 6^{\mathrm{b}}$ & 0.3 & $3.7^{\mathrm{b}}$ & 0.3 & $3.4^{\mathrm{b}}$ & 0.3 & $20 \cdot 6^{a}$ & 0.5 & $20 \cdot 8^{a}$ & 0.6 & $19 \cdot 0^{a}$ & $2 \cdot 3$ & $19 \cdot 4^{a}$ & 2.6 \\
\hline $11 c, 13 t-18: 2 / 11 t, 13 c-18: 2$ & $25 \cdot 5^{\mathrm{b}}$ & 0.2 & $25 \cdot 9^{\mathrm{b}}$ & 0.8 & $26 \cdot 3^{\mathrm{b}}$ & 0.6 & $35 \cdot 1^{\mathrm{a}}$ & 0.8 & $35 \cdot 2^{a}$ & 0.7 & $26 \cdot 0^{\mathrm{b}}$ & $1 \cdot 1$ & $24.9^{b}$ & 1.3 \\
\hline $10 c, 12 t-18: 2 / 10 t, 12 c-18: 2$ & $27 \cdot 5^{\mathrm{a}}$ & 0.2 & $26 \cdot 8^{a}$ & 1.1 & $26 \cdot 9^{a}$ & $1 \cdot 2$ & $11 \cdot 4^{\mathrm{c}}$ & 0.6 & $11 \cdot 8^{\mathrm{C}}$ & 0.6 & $15 \cdot 7^{\mathrm{b}}$ & 1.4 & $18 \cdot 8^{\mathrm{b}}$ & $2 \cdot 3$ \\
\hline $9 c, 11 t-18: 2 / 9 t, 11 c-18: 2$ & $20 \cdot 2^{a}$ & 0.2 & $19 \cdot 9^{a}$ & 0.7 & $20 \cdot 3^{a}$ & $1 \cdot 1$ & $9 \cdot 8^{\mathrm{C}}$ & 0.5 & $10 \cdot 1^{\mathrm{c}}$ & 0.6 & $13 \cdot 6^{\mathrm{b}}$ & 0.9 & $15 \cdot 5^{\mathrm{b}}$ & 1.6 \\
\hline $8 c, 10 t-18: 2 / 8 t, 10 c-18: 2$ & $15 \cdot 9^{\mathrm{a}}$ & 0.1 & $15 \cdot 6^{\mathrm{a}}$ & 0.6 & $14.6^{\mathrm{a}}$ & 0.7 & $7 \cdot 7^{\mathrm{c}}$ & 0.5 & $6 \cdot 5^{\mathrm{c}}$ & 0.7 & $15 \cdot 8^{\mathrm{a}}$ & 1.3 & $10 \cdot 7^{b}$ & 1.4 \\
\hline Subtotal & $89 \cdot 1^{a}$ & 0.2 & $88 \cdot 2^{\mathrm{a}}$ & $3 \cdot 3$ & $88 \cdot 1^{\mathrm{a}}$ & 3.5 & $63.9^{\mathrm{b}}$ & 1.5 & $63 \cdot 6^{\mathrm{b}}$ & 1.4 & $70 \cdot 5^{\mathrm{b}}$ & $6 \cdot 8$ & $69 \cdot 9^{b}$ & $7 \cdot 2$ \\
\hline $11 c, 13 c-18: 2$ & $1.0^{\mathrm{C}}$ & 0.1 & $0.9^{c}$ & 0.2 & $1.0^{\mathrm{C}}$ & 0.1 & $6 \cdot 2^{\mathrm{a}}$ & 0.6 & $6 \cdot 0^{\mathrm{a}}$ & 0.4 & $3.5^{\mathrm{b}}$ & 0.3 & $3 \cdot 1^{\mathrm{b}}$ & 0.1 \\
\hline $10 c, 12 c-18: 2$ & $2 \cdot 7^{\mathrm{C}}$ & 0.1 & $2 \cdot 7^{\mathrm{C}}$ & 0.1 & $3.0^{c}$ & 0.2 & $6 \cdot 4^{a}$ & 0.3 & $6 \cdot 2^{a}$ & 0.3 & $2 \cdot 7^{\mathrm{c}}$ & 0.1 & $3.7^{\mathrm{b}}$ & 0.2 \\
\hline $9 c, 11 c-18: 2$ & $2 \cdot 8^{a}$ & 0.1 & $2 \cdot 6^{a}$ & 0.1 & $2 \cdot 8^{a}$ & 0.1 & $1.6^{\mathrm{b}}$ & 0.3 & $1.8^{\mathrm{b}}$ & 0.3 & $1.8^{b}$ & 0.1 & $1.6^{\mathrm{b}}$ & 0.1 \\
\hline $8 c, 10 c-18: 2$ & $2 \cdot 8^{a}$ & 0.1 & $1 \cdot 7^{\mathrm{a}, \mathrm{b}}$ & 0.1 & $1.9^{a}$ & 0.1 & $1 \cdot 5^{\mathrm{a}, \mathrm{b}}$ & 0.4 & $1 \cdot 6^{\mathrm{a}, \mathrm{b}}$ & 0.4 & $1.5^{\mathrm{b}}$ & 0.2 & $2 \cdot 1^{\mathrm{a}}$ & 0.2 \\
\hline Subtotal & $8 \cdot 3^{\mathrm{b}}$ & 0.2 & $7.9^{\mathrm{b}}$ & 0.5 & $8 \cdot 7^{\mathrm{b}}$ & 0.4 & $15 \cdot 7^{\mathrm{a}}$ & $1 \cdot 1$ & $15 \cdot 6^{\mathrm{a}}$ & 0.9 & $9 \cdot 5^{\mathrm{b}}$ & 0.4 & $10 \cdot 5^{\mathrm{b}}$ & 1.1 \\
\hline
\end{tabular}

t, trans; $c$, cis.

a,b,c Mean values within a row with unlike superscript letters were significantly different $(P<0.01)$.

${ }^{*}$ For details of diets and procedures, see Table 1 and p. 254.

were $20 \cdot 6-20 \cdot 8 \%$ of the total CLA isomers whereas they were only $2.6-3.7 \%$ in the milk and diet (Table 5). The distribution pattern of CLA isomers in the liver TG was closer to that in the liver PL but it was very different from those in the diet and milk. Compared with those in the maternal diet, milk and the liver PL, the total $t / t$ isomers in the liver TG were $19.0-19.4 \%$ whereas total $c / t$-CLA and $c / c$-CLA accounted for $69.9-70.5 \%$ and $9.5-10.5 \%$ total CLA respectively.

\section{Discussion}

The present study is the first to report the relationship between the CLA isomeric distribution in the maternal diet and that in the milk in rats. It was found that the fraction of CLA in the maternal dietary fat was $12.7 \%$ but it was decreased to $7.8-8.6 \%$ in the milk lipids. The results clearly demonstrated that the CLA isomers in the milk reflected those of dietary fat, based on Ag-HPLC analyses. It had previously been shown that under conditions of energy deficiency, lactating women produced milk that resembled the fatty acid pattern of their adipose tissue, but when energy was adequate, the dietary fatty acids were the major influence (Insull et al. 1959). We have previously studied $t$-18:1 isomers in human milk and found its distribution pattern to be similar to that in partially hydrogenated vegetable oil in the diet (Chen et al. 1995). Like t-18:1 isomers, CLA isomeric distribution in milk has to be a reflection of that in the diet since CLA is believed to be not synthesised to any great extent de novo by non-ruminant animals. Previous studies reporting the CLA in animal tissues only measured total CLA content or CLA isomers without complete separation of each isomer (Ip et al. 1991; Chin et al. 1994; Sugano et al. 1997) except for Kramer et al. (1998) who studied distribution patterns of CLA isomers in various tissues of pigs fed a CLA diet, and Ip et al. (1999) who studied the distribution of CLA in rat tissues. It was found that the CLA isomeric profile in pig fats but not liver PL was similar to that in the diet. The present study clearly demonstrated that CLA isomers were transferred from the maternal diet to milk without any significant discrimination.

Incorporation of CLA isomers into liver PL and TG was selective in the suckling rats. Regardless of individual isomers, incorporation of CLA isomers into the liver PL of suckling rats was quantitatively minor $(<0.8 \%$ total fatty acids). The present results clearly showed that $t / t$ CLA isomers were preferentially incorporated into the liver PL and TG whereas for the incorporation of $c / t$ CLA isomers there was partial discrimination. In the maternal diet and milk, total $t / t$ isomers accounted for $2.6-3.7 \%$ total CLA but in the liver PL and TG, they reached $>19 \%$ total CLA isomers. In contrast, total $c / t$ isomers were $>88 \%$ in the maternal diet and milk lipids but they only accounted for $<71 \%$ in the liver PL and TG (Table 5). On the other hand, $c / c$ isomers appeared to be incorporated proportionally into the liver TG but selectively in the liver PL compared with those in the diet. The selective incorporation of CLA isomers into the liver PL and TG is unlikely due to selective absorption. This is because no difference was found in the distribution of CLA isomers in the commercial CLA preparation fed to pigs and in adipose tissue, suggesting that the relative absorption of all the CLA isomers was very similar (Kramer et al. 1998). In addition, the present results found the distribution pattern in the maternal diet was similar to that in the milk, suggesting that all the CLA isomers in the maternal diet were proportionally absorbed and transferred to the mammary gland. In this regard, all the CLA isomers were used to make milk 

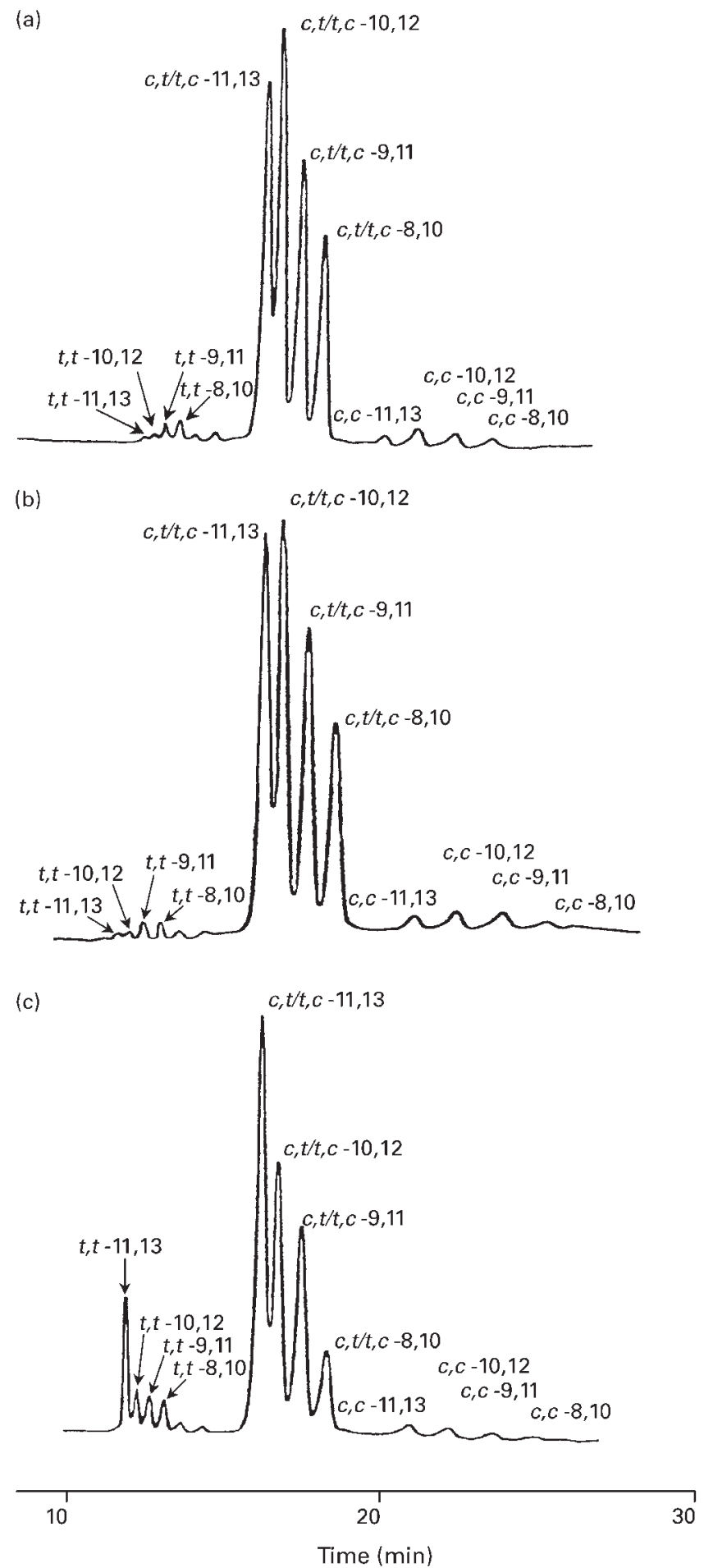

Fig. 1. Typical silver-ion high-performance liquid chromatograms of conjugated linoleic acids as a form of non-esterified fatty acids derived from the maternal dietary fat (a), milk fat (b) and liver phospholipids (c) of suckling rats. Separation was performed in an Ag-impregnated Chrompack analytical column $(4.6 \mathrm{~mm}$ internal diameter $\times 250 \mathrm{~mm})$ and hexane containing $1.4 \%(\mathrm{v} / \mathrm{v})$ acetic acid and $0.014 \%(\mathrm{v} / \mathrm{v})$ acetonitrile was used as a mobile phase at a flow rate of $1 \mathrm{ml} / \mathrm{min}$. $c$, cis; $t$, trans. lipids for secretion and resembled the CLA distribution pattern in the maternal diet. However, the present result contrasts with that of Sugano et al. (1997), who measured the lymphatic recovery of CLA isomers and found that $t / t$ isomers were preferentially absorbed. In their study, the analyses of CLA isomers were made on Supelcowax-20 fused silica capillary column by GLC, which could not completely resolve all the CLA isomers and therefore quantification of each CLA isomer was inaccurate because some isomers were co-eluted. In this sense, identification and quantification of individual CLA isomers became possible only when Ag-HPLC was used to separate $t / t, c / t$, and clc CLA isomers in either diet or animal tissues (Sehat et al. 1998; Ostrowska et al. 2000).

The underlying mechanisms for preferential accumulation of $t / t$ CLA isomers in the liver PL and TG remain unclear. It is difficult to use the availability of CLA isomers in the tissue to explain the differential tissue retention of various CLA isomers. It was possible that accumulation of $t / t$ CLA isomers was the result of slower metabolism, poor substrates for oxidation, and preferred geometrical insertion in the membrane PL. By the same deduction, the low content of $c / t$ CLA isomers in the liver PL could be due to rapid metabolism, oxidation and poor geometrical configuration. In this regard, Sebedio et al. (1997) analysed the conjugated 20:3 and 20:4 isomers in rats fed a diet containing $180 \mathrm{mg} \mathrm{CLA} / \mathrm{d}$ and suggested that some $\mathrm{c} / \mathrm{t}$ CLA isomers were preferentially metabolised to form longer-chain products via desaturation and elongation pathways, thus leading tissue to accumulate more $t / t$ but fewer $c / t$ isomers. The distribution of CLA and its metabolites into rat liver lipid classes has also been reported by Banni et al. (2001). These findings support the present observation that the liver lipids accumulated more $t / t$ isomers $(>19 \%)$ relative to the amount in the diet lipids $(2.6 \%)$.

Incorporation of CLA isomers within each group was also unequal. Within the $t / t$ group, $8 t, 10 t$-CLA and $9 t$, $11 t$-CLA were the major isomers in the diet and milk (Table 5; Fig. 1) but in the liver PL and TG, 11t, $13 t$-CLA became the major isomer. Among the $c / t$ group, $11 c, 13 t / 11 t, 13 c-C L A$ was preferentially incorporated into the liver PL. Within the $c / c$ group, $11 c, 13 c$-CLA and $10 c, 12 c$-CLA appeared to be preferentially incorporated into the liver PL and TG. Together with previous reports (Kramer et al. 1998; Sugano et al. 1997), these observations suggest that incorporation of CLA isomers is tissue-specific and governed by many factors possibly including their geometrical configuration, metabolism, and oxidation.

The present results did not find any significant effect of CLA supplementation in the maternal diet on body weight gain of suckling rats. In fact, the effect of CLA on growth performance and feed conversion efficiency is inconclusive. CLA has been shown to be associated with greater body-weight gain and feed intake in the sows fed a diet containing $2 \%$ CLA compared with those fed a diet containing the same level of linoleic acid (Bee, 2000). In contrast, the feed intake and body-weight gain were significantly reduced in the broiler chickens fed a diet containing $1.5 \%$ CLA compared with the control chickens (Szymczyk 
et al. 2001). Furthermore, Dugan \& Aalhus (1999) found that feeding a diet containing $2 \%$ CLA did not affect average daily gain in pigs. This varying effect of CLA on body weight gain may be due to the different experimental animals, duration of the test period and amount of CLA supplementation.

The information on biological activities of each CLA isomers is very limited. Some evidence suggests that $9 c$, $11 t$-CLA is the active isomer (Ip et al. 1991; Knekt et al. 1996) while several recent reports show that $10 t$, $12 c$-CLA is biologically more potent than $9 c, 11 t$-CLA (Leung \& Liu, 2000; Lin et al. 2001). It is concluded that all the CLA isomers are equally incorporated into the milk lipids but they are selectively incorporated in the liver lipids. The preferential incorporation of some CLA species in relation to the tissue function in vivo is currently unknown. It is premature to conclude that observed preferential incorporation of CLA isomers in the liver of suckling rats is beneficial or adverse unless the biological activity for each CLA isomer has been carefully evaluated in well-defined biological systems.

\section{References}

Banni S, Carta G, Angioni E, Murru E, Scanu P, Melis MP, Bauman DE, Fischer SM \& Ip C (2001) Distribution of conjugated linoleic acid and metabolites in different lipid fractions in the rat liver. Journal of Lipid Research 42, 1056-1061.

Bee G (2000) Dietary conjugated linoleic acid consumption during pregnancy and lactation influences growth and tissue composition in weaned pigs. Journal of Nutrition 130, 2981-2989.

Chen ZY, Chan PT, Kwan KY \& Zhang A (1997) Reassessment of the antioxidant activity of conjugated linoleic acids. Journal of American Oil Chemists' Society 74, 749-753.

Chen ZY, Pelletier G, Hollywood R \& Ratnayake WMN (1995) Trans fatty acid isomers in Canadian human milk. Lipids $\mathbf{3 0}$, $15-21$.

Chin SF, Liu W, Storkson JM, Ha YL \& Pariza MW (1992) Dietary sources of conjugated dienoic isomers of linoleic acid, a newly recognized class of anticarcinogens. Journal of Food Composition and Analysis 5, 185-197.

Chin SF, Storkson JM, Albright KJ, Cook ME \& Pariza MW (1994) Conjugated linoleic acid is a growth factor for rats as shown by enhanced weight gain and improved feed efficiency. Journal of Nutrition 124, 2344-2349.

Cook ME, Miller CC, Park Y \& Pariza MW (1993) Immune modulation by altered nutrient metabolism: Nutritional control of immune-induced growth depression. Poultry Science 72, $1301-1305$.

Dugan MER \& Aalhus JL (1999) Feeding CLA to pigs: Effects on feed conversion, carcass composition, meat quality, and palatability. In Advances in Conjugated Linoleic Acid Research, Vol. 1, pp. 354-368 [MP Yurawecz, MM Mossoba, JKG Kramer, MW Pariza and GJ Nelson, editors]. Champaign, IL: AOCS Press.

Dugan MER, Aalhus JL, Schaefer AL \& Kramer JKG (1997) The effects of conjugated linoleic acid on fat to lean repartitioning and feed conversion in pigs. Canadian Journal of Animal Science 77, 723-725.

Ha YL, Grimm NK \& Pariza MW (1989) Newly recognized anticarcinogenic fatty acids: identification and quantification in natural and processed cheeses. Journal of Agricultural and Food Chemistry 37, 75-81.
Ha YL, Storkson J \& Pariza MW (1990) Inhibition of benz(a)pyrene-induced mouse forstomach neoplasia by conjugated dienoic derivatives of linoleic acid. Cancer Research 50, 1097-1101.

Insull W, Hirsch TJ, James T \& Ahrens EH (1959) The fatty acid of human milk. II. Alterations produced by manipulation of caloric balance and exchange of dietary fat. Journal of Clinical Investigation 28, 443-450.

Ip C, Chin SF, Scimeca JA \& Pariza MW (1991) Mammary cancer prevention by conjugated dienoic derivative of linoleic acid. Cancer Research 51, 6118-6124.

Ip C, Banni S, Angioni E, Carta G, McGinley J, Thompson HJ, Barbano D \& Bauman D (1999) Conjugated linoleic acidenriched butter fat alters mammary gland morphogenesis and reduces cancer risk in rats. Journal of Nutrition 129, 2135-2142.

Kepler CR \& Tove SB (1967) Biohydrogenation of unsaturated fatty acids. Journal of Biological Chemistry 242, 5606-5612.

Knekt P, Jarvinen R, Seppanen R, Pukkala E \& Aromaa A (1996) Intake of dairy products and the risk of breast cancer. British Journal of Cancer 73, 687-691.

Kramer JKG, Sehat N, Dugan MER, Mossoba MM, Yurawecz MP, Roach JAG, Eulitz K, Aalhus JL, Schaefer AL \& Youh KU (1998) Distributions of conjugated linoleic acid (CLA) isomers in tissue lipids classes of pigs fed a commercial CLA mixture determined by gas chromatography and silver ionhigh-performance liquid chromatograph. Lipids 33, 549-558.

Kwan KY, Wang LY, Chan KP \& Chen ZY (1998) Inhibitory effect of linoleic acid on chain elongation and desaturation of 18:2 c,t isomers in lactating and neonatal rats. Lipids 33, $409-416$.

Lee KN, Kritchevsky D \& Pariza MW (1994) Conjugated linoleic acid and atheroclerosis in rabbits. Atheroclerosis 108, 19-25.

Leung YH \& Liu RH (2000) Trans-10, cis-12-conjugated linoleic acid isomer exhibits stronger oxyradical scavenging capacity than cis-9, trans-11 conjugated linoleic acid isomer. Journal of Agricultural and Food Chemistry 48, 5469-5475.

Li Y \& Watkins BA (1998) Conjugated linoleic acids alter bone fatty acid composition and reduce ex vivo bone prostaglandin E2 biosynthesis in rats fed n-6 or n-3 fatty acids. Lipids 33, 417-425.

Lin Y, Kreeft A, Schuurbiers JA \& Draijer R (2001) Different effects of conjugated linoleic acid isomers on lipoprotein lipase activity in 3T3 adipocytes. Journal of Nutritional Biochemistry 12, 183-189.

Miller CC, Park Y, Pariza MW \& Cook ME (1994) Feeding conjugated linoleic acid to animals partially overcomes catabolic responses due to endotoxin injection. Biochemical and Biophysical Research Communications 198, 1107-1112.

Nicolosi RJ, Rogers EJ, Kritchevsky D, Scimeca JA \& Huth PJ (1997) Dietary conjugated linoleic acid reduces plasma lipoproteins and early aortic atherosclerosis in hypercholesterolemic hamsters. Artery 22, 266-277.

Ostrowska E, Dunshea FR, Muralitharan M \& Cross RF (2000) Comparison of silver-ion high-performance liquid chromatographic quantification of free and methylated conjugated linoleic acids. Lipids 35, 1147-1153.

Scimeca JA (1999) Cancer inhibition in animals. In Advances in Conjugated Linoleic Acid Research, Vol. 1, pp. 420-443 [MP Yurawecz, MM Mossoba, JKG Kramer, MW Pariza and GJ Nelson, editors]. Champaign, IL: AOCS Press.

Sebedio JL, Juaneda P, Dobson G, Ramilison I, Martin JC, Chardigny JM \& Christie WW (1997) Metabolites of conjugated isomers of linoleic acids (CLA) in the rat. Biochimica et Biophysica Acta 1345, 5-10.

Sehat N, Yurawecz MP, Roach JAG, Mossoba MM, Kramer JKG \& Ku Y (1998) Silver-ion high-performance liquid chromato- 
graphic separation and identification of conjugated linoleic acid isomers. Lipids 33, 217-221.

Sugano M, Tsujita A, Yamasaki A, Yamada K, Ikeda I \& Kritchevsky D (1997) Lymphatic recovery, tissue distribution, and metabolic effects of conjugated linoleic acid in rats. Journal of Nutritional Biochemistry 8, 38-43.

Szymczyk B, Pisulewski PM, Szczurek W \& Hanczakowski P (2001) Effects of conjugated linoleic acid on growth performance, feed conversion efficiency, and subsequent carcass quality in broiler chickens. British Journal of Nutrition $\mathbf{8 5}$, $465-473$. van den Berg JJM, Cook NE \& Tribble DL (1995) Reinvestigation of the antioxidant properties of conjugated linoleic acid. Lipids 30, 599-605.

Yang L, Leung LK, Huang Y \& Chen ZY (2000) Oxidative stability of conjugated linoleic acid isomers. Journal of Agricultural and Food Chemistry 48, 3072-3076.

Yeung CHY, Yang L, Huang Y, Wang J \& Chen ZY (2000) Dietary conjugated linoleic acid mixture affects the activity of intestinal acyl coenzyme A:cholesterol acyltransferase in hamsters. British Journal of Nutrition 84, 935-941. 